\title{
Erratum to: Does percutaneous dilatational tracheostomy increase the incidence of sternal wound infection - a single center retrospective of 4100 cases
}

\author{
Lachmandath Tewarie $^{1 \dagger}$, Rachad Zayat ${ }^{1 * \dagger}$, Helga Haefner ${ }^{2}$, Jan Spillner ${ }^{1}$, Andreas Goetzenich$^{1}$, \\ Rüdiger Autschbach ${ }^{1}$ and Ajay Moza ${ }^{1}$
}

Unfortunately, after publication of this article [1] it was noticed that the Authors' Contributions section contained a mistake. The correct text can be seen below:

\section{Authors' contributions}

LT and RZ designed the study and developed the database. LT and RZ performed the statistical analyses and drafted the manuscript. RZ wrote the manuscript. AG critically revised the statistical analysis, the study design and the manuscript. AM critically revised the manuscript in cooperation with the co-authors and interpreted the data. $\mathrm{HH}$ critically revised the microbiological findings. RA, as the department chair, supported this study and participated in designing the study. RA and JS critically revised the manuscript. RZ collected the patient data. All the authors have read and approved the submitted version of the manuscript.

\section{Author details}

'Department of Thoracic and Cardiovascular Surgery, University Hospital RWTH Aachen, Pauwelsstrasse 30, Aachen 52074, Germany. ${ }^{2}$ Department of Infection Control and Infectious Diseases, University Hospital RWTH Aachen, Aachen, Germany.

Received: 4 February 2016 Accepted: 5 February 2016

Published online: 08 February 2016

\section{Reference}

1. Lachmandath T, Rachad Z, Helga H, Jan S, Andreas G, Rüdiger A, et al. Does percutaneous dilatational tracheostomy increase the incidence of sternal wound infection - a single center retrospective of 4100 cases. Journal of Cardiothoracic Surgery. 2015;10:155. doi:10.1186/s13019-015-0365-z.

\footnotetext{
*Correspondence: rzayat@ukaachen.de

${ }^{\dagger}$ Equal contributors

'Department of Thoracic and Cardiovascular Surgery, University Hospital RWTH Aachen, Pauwelsstrasse 30, Aachen 52074, Germany

Full list of author information is available at the end of the article

Submit your next manuscript to BioMed Central and we will help you at every step:

- We accept pre-submission inquiries

- Our selector tool helps you to find the most relevant journal

- We provide round the clock customer support

- Convenient online submission

- Thorough peer review

- Inclusion in PubMed and all major indexing services

- Maximum visibility for your research

Submit your manuscript at www.biomedcentral.com/submit 